\title{
Novosti davčnega inšpekcijskega nadzora po ZDAVP-2
}

\author{
UDK: $336.22: 35.075 .6(497.4)$ \\ Polona Kovač \\ Univerza v Ljubljani, Fakulteta za upravo \\ polona.kovac@fu.uni-lj.si \\ Tina Konečnik \\ tina.kon@email.si
}

\section{IZVLEČEK}

Davčni nadzor je nadzor nad izvajanjem in spoštovanjem predpisov s področja obdavčenja, predvsem pa nadzor nad določbami zakonov o obdavčitvi in Zakona o davčnem postopku (ZDavP-2). Davčni inšpekcijski nadzor pomeni vodenje postopka, ki se izvaja pri davčnem zavezancu, gre torej za zunanji nadzor. Davčni inšpekcijski nadzor izvajajo davčni inšpektorji, ki so javni uslužbenci s posebnimi pooblastili. Zakon daje inšpektorjem obsežna pooblastila, ki so potrebna za učinkovito opravljanje nalog inšpekcijskega nadzora. $V$ davčnem inšpekcijskem postopku se najprej upoštevajo pooblastila in ukrepi, ki jih določa posamezen zakon o obdavčitvi, nato ZDavP-2 in Zakon o inšpekcijskem nadzoru. Davčni inšpekcijski postopek je poseben upravni postopek, posebnost le-tega je v nemožnosti izognitve subsidiarne rabe Zakona o splošnem upravnem postopku. Stvarno pristojen za izvajanje davčne inšpekcije je davčni urad Davčne uprave Republike Slovenije, na drugi stopnji Ministrstvo za finance. Prispevek temelji na ZDavP-2, zato so $v$ njem predstavljene bistvene spremembe davčnega inšpekcijskega nadzora, ki jih prinaša omenjeni zakon od 1. 1. 2007, zlasti začetek inšpekcijskega nadzora z vročitvijo sklepa in omejeno trajanje ter načini zaključka inšpekcijskega postopka.

Ključne besede: davčna inšpekcija, upravni postopek, davčni postopek, davčni nadzor, davčni organ, zavezanec, inšpektor, raba ZUP, ZDavP-2

\section{Uvodne opredelitve}

Davčni nadzor obsega nadzor nad izvajanjem oziroma upoštevanjem zakonov o obdavčenju in ZDavP-2 ${ }^{\mathbf{1}}$. Pri tem se subsidiarno uporabljata tudi Zakon o

1 Zakon o davčnem postopku, Uradni list RS, št. 117/06. Gre za tretji zakon o davčnem postopku v slovenskem pravnem redu, pri čemer prvi iz I. 1996 nadzora ni posebej opredeljeval, drugi - ZDavP-1 iz I. 2004 je že vseboval posebno poglavje o nadzoru, pri čemer pa sedanji zakon z začetkom uporabe od 1. 1. 2007 prinaša na tem področju kar nekaj ključnih novosti. 


\section{Novosti davčnega inšpekcijskega nadzora po ZDAVP-2}

inšpekcijskem nadzoru (ZIN) ${ }^{\mathbf{2}}$ in Zakon o splošnem upravnem postopku (ZUP) ${ }^{\mathbf{3}}$. ZDavP-2 $\vee 127$. členu določa, da davčni nadzor obsega (1) nadzor davčnih obračunov pri davčnem organu, (2) nadzor in kontrolo $v$ skladu z zakonom, ki ureja carinsko službo, (3) davčni inšpekcijski nadzor in (4) davčno preiskavo.

Davčni inšpekcijski postopek je poseben upravni postopek (o tem izrecno odločba UstS U-I-252/00), ki je specifičen v več pogledih. Kot upravni postopek obravnava določeno upravno zadevo, ki jo opredeljuje potencialni ali že nastali konflikt med individualno in javno koristjo. Ker gre pri davčnih postopkih pretežno za odločanje o obveznostih strank - zavezancev, je ta konflikt vnaprej toliko bolj poudarjen, kar zavezuje davčni organ pri odločanju k posebni skrbnosti pri iskanju ravnotežja med javnim in zavezančevim interesom. Cilj inšpekcijskega pregleda je zagotoviti kontrolni sistem plačevanja davkov in ob morebitnem neplačilu ustrezno ukrepati. ${ }^{\mathbf{4}}$ Davčni organ ni odgovoren le za uresničevanje javnih koristi pri učinkovitem pobiranju davkov, temveč hkrati za varovanje interesov zavezancev za davek $v$ postopku ${ }^{\mathbf{5}}$, saj mora ravnati po 128 . členu ZDavP-2 posebej $v$ postopkih nadzora tako zavezancu $v$ breme kot tudi $v$ korist. Zaradi zaščite davčnih zavezancev pred samovoljnim ravnanjem pooblaščenih oseb mora biti usmerjen $v$ bistvene stvari, torej dejstva, ki vplivajo na obdavčitev. Davčni nadzor se prednostno torej nanaša predvsem (čeprav ne izključno) na tista dejstva in okoliščine, ki lahko vplivajo na povečanje ali zmanjšanje davčne obveznosti ali vplivajo na prenos davčne obveznosti med davčnimi obdobji.

V letu 2005 je bil v povezavi z upravnim davčnim inšpekcijskim postopkom uveden tudi nov koncept obravnavanja prekrškov zavezancev za davek. Prekrškovni postopek se po začetku uporabe Zakona o prekrških (ZP-1) ${ }^{6}$ od 1. 1. 2005 deli na hitri in redni prekrškovni postopek. Hitri prekrškovni postopek vodi po novem tudi davčni urad $v$ okviru inšpekcijskega nadzora (o tem poudarjeno ZIN-A, 18. člen). Hitri prekrškovni postopek se vodi vzporedno z upravnim, če kršitev davčnih predpisov pomeni podlago za kvalifikacijo prekrška.

Davčni inšpekcijski nadzor kot zunanji nadzor poteka praviloma v prostorih davčnega zavezanca, kjer inšpektorji preverjajo poslovanje zavezanca, pravočasnost

2 Uradni list RS, 56/02, 26/07 (ZIN-A).

3 Uradni list RS, št. 80/99, 70/00, 52/02, 73/04, 119/05, 24/06-UPB2, 105/06-ZUS-1.

4 Tratar in Kruhar Puc, 2005, str. 361.

5 Grivec, 2005, str. 21 po Čok, 2003.

6 Uradni list RS, št. 7/03, 45/04-ZdZPKG, 86/04, 7/05 Skl.US: U-I-19/05-5, 34/05 Odl.US: U-I19/05-11, 44/05, 40/06 (51/06 - popr.) 
plačila davkov ter morebitno davčno utajevanje ${ }^{7}$. Davčni inšpekcijski nadzor je lahko celostni ali delni. $\vee$ primeru celostnega nadzora gre za preverjanje vseh dejstev in dokazov, ki so pomembni za obdavčenje zavezancev. $V$ kolikor je davčni inšpekcijski nadzor delni, obsega posamezna področje poslovanja ali je omejen na enega ali več davkov oziroma na eno ali več davčnih obdobij. Delni nadzor nikakor ne pomeni izvrševanja le dela načela materialne resnice, torej ugotavljanja le dela za obdavčitev relevantnih dejstev oz. odločanje zgolj na podlagi verjetnosti. Na tako tolmačenje je zavajajoče napotovala dikcija ZDavP-1, ki je določal, da celostni nadzor obsega preverjanje vseh dejstev in dokazov, pomembnih za obdavčenje zavezanca. Torej bi bil delni nadzor pač preverjanje le dela relevantnih dejstev. Ta zakon je zato vsebinsko bistveno pravilneje opredelil celostni nadzor kot nadzor nad vsemi področji poslovanja oz. vseh vrst davkov bodisi za eno ali več davčnih obdobij. Prav tako delni nadzor ne pomeni, da $\vee$ teh postopkih ne veljajo vsa pooblastila ter pravice in obveznosti zavezancev po 137.-139. členu tega zakona (o tem izrecno deseti odstavek 138. člena ZDavP-2).

$\checkmark$ davčnem inšpekcijskem postopku je stvarno pristojen na prvi stopnji davčni urad Davčne uprave RS, na drugi stopnji pa Ministrstvo za finance. Krajevno pristojen za odločanje $v$ davčnem postopku je davčni urad, na območju katerega je zavezanec vpisan $v$ davčni register oziroma davčni urad, na območju katerega je ali bi lahko nastala davčna obveznost. Davčni inšpektor pa lahko opravlja naloge na celotnem območju države. Davčni inšpekcijski nadzor izvajajo davčni inšpektorji, ki so javni uslužbenci - uradniki, zaposleni za nedoločen čas. Pooblastila za odločanje $v$ inšpekcijskih postopkih dobe že po zakonu, ki ureja davčno službo, ZIN in ZUP $s$ samo zaposlitvijo na inšpektorskem delovnem mestu.

Davčni inšpekcijski nadzor se opravlja pri pravnih osebah in fizičnih osebah, ki so nosilci dejavnosti. Kadar se opravlja davčni inšpekcijski pregled pri fizičnih osebah, ki opravljajo dejavnost, pooblaščena uradna oseba preveri tudi dejstva, ki se ne nanašajo na poslovanje, če ta dejstva vplivajo na obdavčitev iz dejavnosti, saj se tako izraža namen inšpekcijskega nadzorstva. Glede na ureditev po prejšnjem zakonu je bila dodana usmeritev, da mora biti pooblaščena uradna oseba posebej pozorna na dejstva $\vee$ zvezi z opravljanjem aktivnosti nosilca dejavnosti fizične osebe. $V$ povezavi s 74 . členom ZDavP-2 (ugotavljanje dejstev, ki vplivajo na obdavčitev) se nadzor lahko opravlja tudi pri fizični osebi, ki opravlja neregistrirano dejavnost, če se pri tem ukvarja s posli

7 Med najvplivnejše dejavnike davčnega odpora štejemo višino davčnega bremena, ki postaja vedno hujše. Vendar pa ni znano, katera je absolutna višina davčnega bremena na katero zavezanci reagirajo z odporom (Veršnik, 2004, str. 14). 
Polona Kovač, Tina Konečnik

Novosti davčnega inšpekcijskega nadzora po ZDAVP-2

oz. prejema dohodke, ki so predmet obdavčitve. Pri pravnih osebah se pri davčnem inšpekcijskem nadzoru nadalje preverjajo razmerja med lastniki oz. člani pravnih oseb in pravnimi osebami.

\section{Subsidiarnost $v$ davčnem inšpekcijskem postopku}

Upravni postopek je sistem procesnih pravil, po katerih ravnajo upravni in drugi organi, kadar odločajo o upravnih stvareh. O posebnem upravnem postopku pa govorimo tedaj, kadar pravila splošnega upravnega postopka ne zadoščajo; gre torej za specifična področja, ki jih urejajo posebni zakoni. Ko govorimo o davčnem inšpekcijskem postopku kot o posebnem upravnem postopku, je treba posebej poudariti subsidiarnost, in sicer gre za vprašanje hierarhije predpisov. Temeljni postopkovni zakon je seveda ZDavP-2, vendar imajo pri davčnem inšpekcijskem postopku glede na hierarhijo prednost:

- $\quad$ redpisi Evropske skupnosti (evropske direktive) ${ }^{\mathbf{8}}$,

- sledi posamezen zakon o obdavčitvi (zakoni o posamezni vrsti davka, npr. o davku na dodano vrednost, dohodnini, davku na motorna vozila ...),

- nadalje sledi ZDavP-2, s podrejeno rabo zakona o davčni službi zlasti v zvezi s pravili o pristojnosti (krajevna in personalna) in

- nenazadnje sledita še ZIN in ZUP.

ZDavP-2 je torej temeljni zakon, ki ureja postopek davčnega inšpekcijskega nadzora, kljub temu pa je treba poudariti, da omenjeni zakon ni zgolj postopkovni predpis, saj vsebuje celo vrsto materialnih določb, ki so pretežno urejene $\vee$ zakonih o obdavčenju, deloma pa tudi $\vee$ tem zakonu. ${ }^{9}$ ZDS-1 ter ZIN pa sta predpisa, ki davčni postopek urejata predvsem organizacijsko. ZIN je krovni ali sistemski zakon, ki se uporablja za delovanje vseh inšpekcij z vseh upravnih področij; ureja predvsem načela inšpekcijskega nadzora, pooblastila ter ukrepe inšpektorjev. ZIN poleg postopkovnih določb vsebuje tudi materialne ter organizacijsko-tehnične določbe. ZDS-1 pa je temeljni zakon, ki ureja naloge, organizacijo, pristojnosti ter pravice in dolžnosti zaposlenih $\vee$ Davčni upravi RS. Nedvomno pa je temeljni zakon, po katerem morajo postopati vsi upravni organi in sploh izvršilni organi ter organi lokalnih skupnosti in

8 ZDavP-2 v 2. odstavku 1. člena določa, da so evropske direktive sestavni del slovenskega pravnega reda; prav tako iz evropskih direktiv izhaja obveznost medsebojnega sodelovanja med državami članicami Evropske unije pri davčnih postopkih, kot primer pomoč pri izvršbi, izogibanje dvojni obdavčitvi itd.

9 Jerovšek, 2005, str. 287 
nosilci javnih pooblastil, ko odločajo o upravnih stvareh, ZUP. ${ }^{10}$ ZUP se torej subsidiarno uporablja tudi $\vee$ davčnih postopkih, predvsem glede temeljnih načel ZUP, ki jih morajo spoštovati tudi davčni organi. Primerjava postopkovnih določb ZDavP-2 in ZUP-a pokaže, da so postopkovna vprašanja, ki so drugače urejena $\vee$ ZDavP-2 kot $\vee$ ZUP-u, relativno maloštevilna. ZUP se $\vee$ davčnih inšpekcijskih postopkih uporablja predvsem glede institutov kot so: jezik $\vee$ postopku, vročanje, zastopstvo strank, pravna sredstva idr.

Davčni organi subsidiarne rabe ZUP-a pogosto ne spoštujejo, saj menijo,

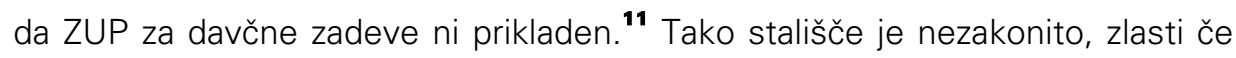
se pri opuščanju rabe ZUP-a spregleda ali omeji kakšna (ustavna) postopkovna pravica. Tako ravnanje je razlog za izpodbijanje davčne odločbe zaradi kršitev pravil postopka. Uporaba ZUP-a je obvezna, če gre za upravno stvar; za odločanje o pravici, obveznosti ali pravni koristi posameznika, pravne osebe ali druge stranke ${ }^{\mathbf{1 2}}$. Uporabe ZUP-a se torej ne da "izločiti" glede na celotno pravno ureditev $\vee$ Republiki Sloveniji, sicer bi bile prizadete pravice strank, kajti ZUP omogoča njihovo minimalno zagotavljanje ne glede na upravno področje.

Kot primer obveznega spoštovanja oz. upoštevanja načela subsidiarnosti je smiselno navesti naslednjo sodbo (Sodba Upravnega sodišča RS, U 2193/2002-20, z dne 22. 11. 2004): "...Neutemeljeni so tudi ugovori, da je tožena stranka kršila določbe ZUP, ker ni ravnala po "preiskovalnem" načelu in ni sama ugotavljala določenih dejstev, da je odločala po prostem preudarku in podlage za tako ravnanje $v$ odločbi ni obrazložila ter, da bi morala po uradni dolžnosti upoštevati splošno znana dejstva. ZDavP je $v$ razmerju do ZUP (na kršitev katerega se tožnik sklicuje), specialen predpis in je zato tožena stranka dolžna upoštevati določbe ZDavP. Davčni postopek je poseben upravni postopek in ZDavP omogoča ugotavljanje dejanskega stanja in s tem dokazovanje poslovnih dogodkov z verodostojnimi listinami in tudi drugimi dokaznimi sredstvi..."

Davčni inšpekcijski postopek je torej poseben upravni postopek, ki je specifičen $v$ več pogledih. Zakon, ki ga ureja, je eden najpogosteje spreminjajočih se zakonov, kar je slabost za davčne inšpektorje, prav tako pa tudi za zavezance za davek. $V$ davčnem inšpekcijskem postopku je močno poudarjen konflikt med javno in zasebno koristjo; celotno delovanje inšpekcije pa je $\vee$

10 Kar določata 1. in 3. člen ZUP. Nekatera upravna področja pa so po svoji naravi tako svojstvena, da o upravnih stvareh na takih področjih ni mogoče postopati po ZUP-u oziroma pravila glede na naravo upravne stvari ne ustrezajo. ZUP $v$ 3. členu določa, da se na upravnih področjih, za katera je z zakonom predpisan poseben upravni postopek, postopa po določbah posebnega zakona. Po določbah ZUP-a pa se postopa $v$ vseh vprašanjih, ki niso urejena $s$ posebnim zakonom.

11 Šinkovec, 2002, str. 46.

12 Prvi odstavek 1. člena ZUP. 
javnem interesu, kar predvsem poudarja ZIN $\vee$ okviru načel inšpekcijskega postopka. Inšpekcijski postopki so torej usmerjeni predvsem $\vee$ varovanje javnega interesa - pomembna je zakonitost delovanja, kar je $\vee$ korist družbe in posameznikov, ki se na to zanesejo po načelu pravne varnosti. ${ }^{\mathbf{3}}$

\section{Načela davčnega inšpekcijskega postopka}

Načela $v$ davčnem postopku so pomembna predvsem zaradi reševanja morebitnega konflikta med učinkovitostjo pobiranja davkov ter varstvom pravic zavezanca za davek. ${ }^{14}$ Načela naj bi predvsem usmerjala delovanje organa, omogočala pravilno uporabo materialnega prava, zagotavljala procesna jamstva stranki, omejevala organ, da ne uporablja predpisov na nedovoljen način idr. $V$ davčnem inšpekcijskem postopku vsa načela veljajo dopolnilno, saj ni mogoče govoriti o hierarhiji le-teh (niso predmet subsidiarnosti). Kljub temu $\vee$ davčnih zadevah velja naslednje sosledje načel:

- načela po sodni praksi Evropskega sodišča za človekove pravice in svoboščine ter sodišča Evropskih skupnosti,

- načela po ZUP-u (6.-14. člen),

- načela po ZDavP-2 (4.-10. člen, za davčni inšpekcijski nadzor posebej še 128. in 134. člen),

- načela po ZIN-u (4.-7. člen).

Načela davčnega postopka morajo biti usklajena z načeli, ki izhajajo iz sodne prakse evropskih sodišč. Predvsem se poudarja načelo antidiskriminacije, prepoved retroaktivnosti, načelo obrazložitve oblastne odločitve, prepoved dvojnega obdavčevanja ${ }^{\mathbf{1 5}}$ in druga.

Novi zakon o davčnem postopku pa je $v$ primerjavi z ZDavP-1 ${ }^{\mathbf{1 6}}, \mathrm{z}$ ureditvijo temeljnih načel davčnega postopka, prinesel dodano vrednost. $\vee$ drugem poglavju z naslovom "Načela davčnega postopka" je prvo in tudi najpomembnejše načelo,

13 Kovač, 2006 a, str. 273

14 Kovač, 2006 b, str. 8.

15 Načelo prepovedi dvojnega obdavčevanja poudarja tudi sodna praksa (npr. Sodba Upravnega sodišča št. U 2264/2004-12, z dne 13. 12. 2005): "Odločitev tožene stranke je pravilna, saj je po presoji sodišča, $v$ ZDoh obravnavan tisti davek, ki je bil obračunan in plačan pravilno, torej tudi ob upoštevanju veljavnih Mednarodnih pogodb oziroma Sporazumov, sklenjenih z namenom izogibanja dvojnemu obdavčenju, na pa tudi morebitno (napačno) preplačan davek, za katerega lahko plačnik, glede na določbe Sporazumov, vedno zahteva refundacijo." 


\section{Novosti davčnega inšpekcijskega nadzora po ZDAVP-2}

načelo zakonitosti (legalitete), za ureditev katerega je pomemben razlog predvsem dejstvo, da davčni organi nemalokrat odločajo po diskrecijski pravici, prav tako pa tudi dejstvo, da gre za naložitev dajatev in s tem poseganje $v$ svobodo posameznikov ${ }^{17}$. Nedvoumno pa je temeljni pogoj za zakonito in pravilno odločanje nepristranskost. Naslednje pomembno načelo je načelo sorazmernosti (ali je ukrep nujen in primeren oz. potreben), ki ga določa tudi ZIN $\vee 7$. členu. Poleg omenjenega načela sorazmernosti ZIN določa še načelo javnosti, načelo samostojnosti, ki se kaže tako na organizacijski (DURS) kot na individualni (inšpektor) ravni ter načelo varstva javnega interesa in zasebnih interesov. Davčni inšpektor mora ugotoviti vsa dejstva, ki so pomembna za zakonito odločitev (prav tako tudi dejstva, ki so $v$ korist zavezanca za davek); gre za načelo materialne resnice. Pri tem je pomembno poudariti, da mora organ ugotoviti vsa dejstva z najvišjo stopnjo prepričanja - to je z gotovostjo. ${ }^{\mathbf{1 8}}$ Davčni inšpekcijski nadzor se opravi tudi po temeljnih načelih ZUP. Med njimi je z vidika davčnega inšpekcijskega nadzora treba izpostaviti načelo proste presoje dokazov, ki določa prosto presojo dokazov, ki ne sme biti usmerjena oziroma dirigirana (10. člen ZUP in 76. ter povezani členi ZDavP-2). Načelo proste presoje dokazov predstavlja vrednostni proces pravilnega selekcioniranja dokazov, glede na dokazno moč posameznih dokazov.

Posebej je $v$ sodni praksi poudarjeno načelo zaslišanja stranke ${ }^{\mathbf{1 9}}$, katerega kršitev je nemalokrat razlog za izpodbijanje odločbe zaradi kršitev pravil postopka (9. člen in drugi odstavek 237. člena ZUP). Kot primer se lahko navede sodba Upravnega sodišča U 241/2001, z dne 21. 11. 2002: "Tožena stranka je dopolnjevala ugotovitveni postopek, zato ima tožeča stranka prav, ko trdi, da izpodbijana odločba temelji na novih dejstvih in okoliščinah, s katerimi ni bila seznanjena, zato je bilo kršeno načelo zaslišanja stranke $v$ upravnem postopku.

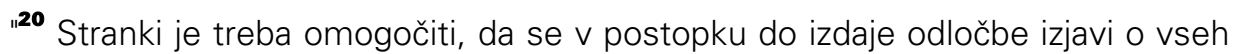

16 Uradni list RS, št. 54/04, 57/04-ZDS-1, 109/04 Odl. US: U-I-356/02-14, 128/04 Odl. US U-I166/03-12, 139/04, 56/05 Skl. US U-I-159/05-04, 96/05-ZRTVS-1, 100/05 Odl. US U-I-159/05-14, 109/05, 21/06 - UPB2.

17 Kovač, 2006 b, str. 9.

18 Načelo materialne resnice določata ZUP $\vee$ 8. členu in ZDavP-2 v 5. ter 128. členu. Oba predpisa $v$ omenjenih členih določata, da lahko organ na podlagi verjetno izkazanih dejstev odloči le $v$ primeru, kadar to dopušča zakon, sicer se namreč odloči le na podlagi z gotovostjo ugotovljenih dejstev. Prim. 74. člen in povezane ZDavP-2 o skrajšanem in posebnem ugotovitvenem postopku.

19 Pravica do informacij ter pravica "biti slišan « oz. načelo zaslišanja, sta načeli, ki se močno poudarjata $v$ okviru načel upravnega postopka $v$ evropskem pravu ter evropskem upravnem sistemu in predstavljata temelj dobro delujoče uprave. Cilji dobro delujoče uprave pa so predvsem demokratičnost, transparentnost in odprtost $v$ postopku sprejemanja odločitev (po Nehl, 1999, str. 17).

20 Po Mužina, 2004, str. 349. 
Polona Kovač, Tina Konečnik

\section{Novosti davčnega inšpekcijskega nadzora po ZDAVP-2}

dejstvih in okoliščinah, ki imajo vpliv na obdavčenje. $V$ kolikor se slednje upošteva, ni razloga, da bi prišlo do kršitve omenjenega načela. Kot primer Sodba Vrhovnega sodišča št. I UP 1379/2002-3, z dne 14. 12. 2005: "Kot neutemeljen je sodišče zavrnilo tožbeni ugovor, da je bilo $v$ postopku kršeno načelo zaslišanja stranke. Tožeči stranki je bil vročen zapisnik o inšpekcijskem pregledu, nanj je dala tudi pripombe, na katere je prvostopni davčni organ $v$ prvostopni odločbi odgovoril. Glede na to je imela tožnica možnost izjaviti se o ugotovitvah organa pred odločitvijo $v$ tej zadevi, zato načelo zaslišanja stranke $v$ upravnem postopku ni bilo kršeno. "

Pomembnejše načelo je tudi načelo varovanja davčne tajnosti, ki jo morajo varovati zaposleni $v$ davčnem organu oz. vsi, ki zaradi narave svojega dela pridejo v stik s podatki ali dokumenti, ki so označeni kot davčna tajnost. Načeli, ki bremenita davčne zavezance, pa sta določeni kot načelo zakonitega in pravočasnega izpolnjevanja in plačevanja davčnih obveznosti ter načelo dolžnosti dajanja podatkov; ti morajo biti pravilni, resnični in popolni.

Davčno inšpekcijo dodatno zavezuje po 134. členu ZDavP-2 načelo izbire zavezancev oz. predmeta nadzora $v$ davčnih inšpekcijskih postopkih, ki temelji na ustavnih kavtelah enakosti pred zakonom in prepovedi zlorabe oblasti (načelo pravne države). Dejansko se vseh zavezancev namreč ne more nadzirati glede vseh obveznosti v vseh časovnih obdobjih, niti to ne bi bilo smiselno. Nekateri parcialni statistični podatki kažejo, da je obseg nadzora v praksi na letni ravni približno $5 \%$ zavezancev, kar je z vidika učinkovitosti signifikanten delež, saj naj bi po analizi Organizacije za ekonomsko sodelovanje in razvoj in delnih študijah DURS pri obračunih in ob možnosti predizpolnjenih obrazcev napovedi prihajalo do neskladnosti med podatki davčnega organa in zavezanca le $\vee$ 20-30\%, sicer se beleži popolno ujemanje. ZDavP-2 na novo uvaja podrobnejšo opredelitev načela izbire zavezancev za davčni inšpekcijski nadzor, saj gola opredelitev t. i. objektivnih meril brez podrobnejših napotil ne onemogoča arbitrarnosti. (Pri tem zakon nedosledno uporablja izraze načela, merila in kriteriji ter metode.) Izbira zavezancev za davčni inšpekcijski nadzor mora biti popolnoma neodvisna od posameznikov in se lahko veže le na določene abstraktne značilnosti posameznih zavezancev po vnaprej določenih merilih (npr. promet nad določenim zneskom, določena dejavnost in območje) in naključnem izboru. Glavni merili izbire sta (1) enakomerno nadziranje vseh zavezancev za davek ${ }^{\mathbf{2 1}}$ in (2) pomembnost davka, ki ga zavezanec za davek prispeva $\checkmark$ javnofinančnih prihodkih, torej višina davka kot relativni delež proračuna. Drugo merilo posega $\vee$ prvo oz. posamezne zavezance pravzaprav ponderira.

21 enakomernih razporeditvah inšpekcijskih pregledov gl. Nagode, 2005, str. 12. 
Na ta način se nastavi t. i. analiza tveganja, kateri in koliko so določeni zavezanci podvrženi k nepravilnostim pri izpolnjevanju davčnih obveznosti. $\vee$ tem smislu ima višjo oznako rizičnosti zavezanec, za katerega je po splošnih elementih (npr. določena dejavnost) ali neposredno lastnih kršitvah davčnih predpisov bolj verjetno, da bo pri njem ugotovljena nepravilnost, kar izhaja iz predhodnih ugotovitev $\vee$ postopkih nadzora (inšpekcijskih ali drugih po 127. členu). Poleg verjetnosti utaje se upošteva tudi razmerje med potencialno največjo davčno obveznostjo in stroški nadzora. Da bi bilo zagotovljeno enakopravno obravnavanje zavezancev, se uporablja različne metode in njihove kombinacije, po katerih se $v$ načrte nadzora vključuje tudi zavezance, ki opravljajo neregistrirano dejavnost (in zanje davčni organ izve z zbiranjem informacij). Na podlagi teh treh osnovnih meril se $z$ uporabo statističnih metod zagotovi naključni izbor posameznega zavezanca. $S$ tem se zagotavljata enakost zavezancev in objektivnost oz. nepristranskost davčnega organa oz. pooblaščene uradne osebe kot izraza temeljnega načela zakonitosti (120. člen Ustave RS). Podrobneje glede na splošne značilnosti zavezance za nadzor davčni organ (posamezni davčni urad $v$ sodelovanju z generalnim) opredeli v letnem načrtu inšpekcijskega nadzora. Poleg celostnih in delnih nadzorov se $v$ letnem načrtu določi tudi hitre preglede obveznosti za tekoče leto za večje število zavezancev (npr. glede obračunov DDV ali popisov zalog) in t. i. akcije, to so krajši pregledi preventivne narave, ki zajemajo pregled posameznih oznak obračuna po vnaprej znanem in omejenem obsegu dokumentacije (npr. računi za nabavo osnovnih sredstev). Izven letnega načrta nadzora se inšpicira zavezance, če tako predlagajo drugi, nedavčni državni organi na podlagi ugotovitev iz njihove pristojnosti. Enako velja, če sum $\vee$ pravilnost poslovanja vzbudijo ugotovitve $\vee$ postopku (neinšpekcijskega) davčnega nadzora. Glede slednjega konkretno peti odstavek 129. člena glede kontrole obračunov določa, da se inšpekcijski postopek zoper zavezanca za obračun uvede, če se pri notranjem nadzoru ugotovi nepravilnosti, vendar niso znana vsa dejstva, potrebna za obdavčitev, zato ne more že kontrolor izdati odločbe. Podobno določa peti odstavek 131. člena o davčni preiskavi, kajti v primeru utemeljenosti suma nepravilnosti se začne inšpekcijski postopek, pri čemer se $v$ sklepu po 135. členu tega zakona zavezanca seznani z dotedanjimi ugotovitvami iz preiskave, saj se lahko $\vee$ preiskavi zbrani podatki in dokazi uporabijo $v$ inšpekcijskem postopku. Zavezanec nima pravice zahtevati določen način izbora, saj bi posredno lahko prišlo do zlorab. Če zavezanci kršijo davčna pravila, so poleg tega, da se zoper njih vodijo postopki davčnega nadzora in izvršbe, tudi prekrškovno in kazensko odgovorni. $V$ kolikor pa kršitve načel zagrešijo davčni organi, je odločba izpodbojna in se praviloma odpravi, razveljavi ali spremeni prek pravnih sredstev $v$ davčnem postopku ali $v$ sodnih postopkih. 


\section{Potek davčnega inšpekcijskega postopka}

\subsection{Začetek postopka}

Upoštevaje zakonske določbe inšpekcijski postopek praviloma obsega več faz, od priprave do vročitve sklepa o nadzoru (formalni začetek nadzora), sledi dejanski nadzor pri zavezancu (najprej uvodni razgovor, nato ugotavljanje in dokazovanje dejstev), ukrepanje in sklepno evidentiranje ugotovitev in ukrepov $\checkmark$ okviru davčnega inšpekcijskega nadzora.

Davčni inšpekcijski postopki se vedno začnejo po uradni dolžnosti ("ex offo"), kar delno spreminja institut samoprijave, ki jo zakon dopušča od 1. 1. 2006. V kolikor se davčni inšpekcijski postopek začne po uradni dolžnosti, je kot pobudnik za uvedbo postopka poklican pristojni državni organ. ZDavP-2 v primerjavi z ZDavP-1 odpravlja obvezno obvestilo davčnemu zavezancu o začetku inšpiciranja davčnega organa. ZDavP-2 določa, da se davčni inšpekcijski postopek prične $z$ vročitvijo sklepa zavezancu o davčnem inšpiciranju. Tretji odstavek 135. člena ZDavP-2 določa, da se sklep ne vroči, v kolikor bi se na ta način ogrozil namen inšpekcijskega nadzora. $V$ tem primeru se kot začetek postopka šteje kakršnokoli dejanje, ki ga $\vee$ namen davčnega inšpiciranja opravi davčni organ. "Sklep" je v tem primeru le ustno naznanjen, vključno s siceršnjo vsebino sklepa o obsegu nadzora in pravici zavezanca, da sodeluje $v$ postopku, kar se zapiše $v$ zapisnik o nadzoru. Zoper pisni ali ustni sklep ni pritožbe, kar je izraz varstva javne koristi ${ }^{22}$. Primerno časovno obdobje, ki ga ima davčni zavezanec na razpolago, da se pripravi na davčni inšpekcijski nadzor, zagotavlja pravilo, da inšpektor lahko začne opravljati nadzor, ko preteče osem dni po vročitvi sklepa zavezancu. $\vee$ razmerju do povprečnega zavezanca bo postopek torej potekal kot prej (najprej prejme pisni akt organa, nato sledi dejanski nadzor).

Toda navidez zgolj redakcijske spremembe imajo velik pomen z vidika prej spornega trenutka začetka inšpekcijskega nadzora glede dopustnosti samoprijave. Samoprijava je bila po ZDavP-1 enako kot po ZDavP-2 namreč možna do vročitve sklepa o nadzoru, kar je po ZDavP-1 pomenilo možnost vložitve samoprijave po prejemu obvestila in je izničilo smisel nadzora. Zato je zdaj drugače ko zavezanec prejme prvi pisni dokument od davčnega organa, tj. sklep o nadzoru, je rok za samoprijavo že iztekel. Čeprav je obvestilo kot zakonska obveza odpravljeno, je ravno zaradi nemožnosti vložitve samoprijave po vročitvi sklepa ponekod praksa, da davčni organ zavezanca neformalno (po telefonu) obvesti o

22 Kovač, 2006, str. 282. 
predvidenem nadzoru in $v$ kratkem sledeči vročitvi sklepa. Samoprijava je namreč oblika spodbujanja zavezancev $k$ izpolnitvi davčnih obveznosti, četudi naknadno, zato zakon tovrstne zavezance ekskulpira prekrškovne odgovornosti (396. in 399. člen ZDavP-2). Taka praksa opozarjanja je v skladu z varstvom pravic zavezancem, če ne gre za ogroženost javne koristi, ne more pa je zavezanec zahtevati oz. uveljavljati kršitve npr. načela zaslišanja stranke, če predhodnega opozorila ni. Bistvo instituta samoprijave ostaja isto; gre za to, da davčni zavezanec ni kaznovan za prekršek, če je prekršil zakonska določila in plačal premalo davka, vendar le, če bo razkril prave podatke o davčni obveznosti pred začetkom davčnega inšpiciranja. ${ }^{\mathbf{2 3}}$ Inštitut samoprijave naj bi spodbujal zavezance $\mathrm{k}$ prostovoljnemu izpolnjevanju davčnih obveznosti ${ }^{\mathbf{2 4}}$ in $\mathrm{k}$ temu, da se morebitne nepravilnosti $v$ davčnih obračunih ali $v$ davčnih napovedih, ki jih zavezanci ugotovijo kasneje, sporočijo davčnemu organu.

Kot relativno nov institut je določena davčna preiskava (131. člen). Davčno preiskavo začne davčni organ tako, da izda nalog za preiskavo, v katerem se navedejo okoliščine, iz katerih izhajajo razlogi za sum, oziroma dejanja in ukrepi, zaradi katerih se bo davčna preiskava opravila ter predmet davčne preiskave. Po opravljeni davčni preiskavi bo inšpektor izdelal zaključno poročilo, v katerem bodo opisane ugotovitve davčne preiskave. Če se bo na podlagi ugotovitev izkazalo, da so razlogi za sum utemeljeni, davčni inšpektor lahko začne postopek davčnega inšpiciranja.

Davčni inšpektor se na začetku inšpiciranja z zavezancem za davek dogovori o datumu za uvodni pogovor, in sicer najpogosteje po telefonu. Davčni inšpektor naj bi na začetku pregleda davčnega zavezanca seznanil za kakšen pregled gre (npr. davek od odhodka pravnih oseb) in na katero leto se davčno inšpiciranje nanaša ${ }^{\mathbf{2 5}}$. Tako mora sklep o začetku postopka vsebovati obdobje obdavčenja, vrste davkov oziroma predmet davčnega inšpiciranja, opozorilo o pravici do sodelovanja davčnega zavezanca $\vee$ postopku inšpiciranja ter o pravnih posledicah morebitnega oviranja davčnega inšpiciranja ${ }^{\mathbf{2 6}}$. Davčni inšpekcijski postopki se lahko začnejo tudi brez najave oz. predhodno poslanega sklepa, vendar le kadar gre za sum večjih davčnih utaj ali za vnaprej določene akcije.

23 GI. 55. in 63. člen ZDavP-2 v povezavi s kazenskimi določbami.

24 Spodbujanje prostovoljnega izpolnjevanja obveznosti (Voluntary Compliance) je eno od pomembnejših načel vsake davčne uprave. Nepogrešljivo orodje za spodbujanje prostovoljnega izpolnjevanja davčnih obveznosti je predvsem učinkovit sistem sankcij oz. glob (po Silvani, Baer, 1997, str. 11, 25).

25 Kruhar Puc, 2004, str. 50.

26 Četrti odstavek 135. člena ZDavP-2. 


\subsection{Ugotovitveni in dokazni postopek}

$\mathrm{Na}$ začetku davčnega inšpekcijskega postopka je treba zavezanca za davek opozoriti, da inšpiciranju lahko prisostvuje ter da lahko imenuje osebo za dajanje podatkov in pojasnil (138. člen ZDavP-2). Davčni inšpekcijski nadzor se opravlja pri zavezancu za davek, ki opravlja dejavnost in to $\vee$ prostorih kjer opravlja dejavnost ter kjer vodi in hrani poslovne knjige in evidence. Ne opravlja pa se $v$ prostorih, ki jih zavezanec ni določil za svoj sedež ali poslovni prostor. Če zavezanec ne more zagotoviti primernega prostora za inšpekcijski nadzor, se le-ta lahko opravlja tudi v prostorih davčnega organa, po novem lahko tudi v prostorih pooblaščenca ${ }^{\mathbf{2 7}}$. Inšpekcijski nadzori se opravlja $\vee$ poslovnem času, lahko pa tudi izven poslovnega časa, kadar je to potrebno.

Pooblaščena uradna oseba in zavezanec $v$ postopku bolj ali manj skladno sodelujeta drug z drugim. Da pri tem ne bi prišlo do prekoračitve pooblastil, hkrati pa bi se zagotovil učinkovit nadzor, zakon določa skupek pristojnosti, pravic in obveznosti obeh glavnih udeležencev postopka, praviloma inšpektorja in zavezanca. Pooblastila inšpektorjev in pravice oz. obveznosti zavezancev, ki jih določajo 138.člen in povezani členi, bi bilo smotrno strukturirati v zakonu v zaporednih, a ločenih členih, kajti določena razmerja so lahko mešana, npr. sodelovanje zavezanca pri inšpekcijskem pregledu je hkrati njegova pravica in obveznost (t. i. dolžnostno upravičenje). Zakon je torej nedosleden, še sploh če upoštevamo nepotrebnost navajanja tistih pooblastil, ki jih že določa ZIN (ZDavP-2 nekatera povzema, druga ne, veljajo vsa). Splošno pa lahko ugotovimo, da se nabor pravic zavezancev s časom povečuje (prim. ZDavP, ZDavP-1, ZDavP-1B in ZDavP-2, poleg določb $v$ tem poglavju gl. še npr. enotno tolmačenje predpisov prek navodil ministra za finance ali generalnega direktorja DURS/CURS, možnost samoprijave, možnost pregledovanja dokumentacije pri pooblaščencih zavezancev, skrajšanje roka za zaseg dokumentacije, podaljšanje roka za pripombe na zapisnik, tek roka za obnovo postopka pri pristojnem organu od dneva sestave zapisnika ipd.).

Davčni zavezanci za davčne potrebe vodijo poslovne knjige in dokumentacijo, ki morajo biti vodene pravilno in zakonito. $K$ predložitvi pravilnih, resničnih in popolnih podatkov jih zavezuje že načelo dolžnosti dajanja podatkov, ki ga določa novi ZDavP-2. Prav tako mora davčni zavezanec navesti vsa dejstva in dokaze za svoje zahtevke. Navedeno potrjuje tudi sodba Upravnega sodišča št. U 2236/2002-29, z dne 7. 11. 2005: "V davčnem postopku se ugotavljajo dejstva in s tem dokazujejo poslovni dogodki predvsem z verodostojnimi listinami,

27 Kruhar Puc, Galič, 2006, str. 34-35. 
lahko tudi z drugimi dokaznimi sredstvi, vendar pa je dokazno breme vedno na strani davčnega zavezanca, ki mora za svoje trditve predložiti verodostojne dokaze. Čeprav ZDavP vrste dokaznih sredstev ne omejuje, jih $v$ določenem obsegu omejuje sama narava davčnega postopka, oz. omejujejo določbe materialnih predpisov, ki posamezne poslovne dogodke priznavajo le, če temeljijo na pravilnih in verodostojnih knjigovodskih listinah. Knjigovodska listina pa je verodostojna, če se pri njenem kontroliranju pokaže, da strokovna oseba, ki ni sodelovala $v$ poslovnem dogodku, lahko na njeni podlagi jasno in brez dvomov spozna naravo in obseg poslovnega dogodka." Da bi davčni inšpektor lahko ugotovil višino davčne obveznosti, ima pravico pregledati poslovne prostore, naprave, blago, stvari, predmete, listine, poslovne knjige, pogodbe in druge dokumente, ki omogočajo vpogled $v$ poslovanje davčnega zavezanca ${ }^{\mathbf{2 8}}$. Osmi odstavek 138. člena ZDavP-2 določa, da pooblaščena oseba lahko zaseže listine, baze podatkov, predmete, vzorce in drugo blago za največ $30 \mathrm{dni}, \mathrm{v}$ kolikor je to potrebno za zavarovanje dokazov, izjemoma pa se lahko pri dolgotrajnih davčnih inšpekcijskih pregledih ta rok podaljša za največ 90 dni. Pri davčnih inšpekcijskih postopkih gre praviloma za dolgotrajne ugotovitvene postopke. $K$ temu največ prispeva morebitna cenitev davčne osnove, ki je poseben ugotovitveni postopek, pri katerem je davčni organ tisti, ki mora dejstva na podlagi katerih izdaja davčno odločbo, dokazati. $V$ tem primeru zavezanec tako odmerjeni davek lahko izpodbija le, če predloži dokaze, da je davčna osnova nižja ali ni pravilno ugotovljena, torej na temelju obrnjenega dokaznega bremena ${ }^{29}$. ZDavP-2 določa odmero davka $\vee$ posebnih primerih $\vee$ 68. členu, kjer je določeno, da je davčni organ upravičen ceniti davčno osnovo, kadar zavezanec za davek ne vloži davčne napovedi ali ne predloži obračuna davka oziroma kadar davčni organ ugotovi, da davčna napoved ali davčni obračun temelji na neresničnih podatkih, kadar delodajalec ne predloži podatkov o davčnem odtegljaju od dohodkov iz zaposlitve ter kadar davčni organ ugotovi, da napovedani prihodki niso sorazmerni napovedanih odhodkom. Najpogostejši primer ocene davčne osnove je podan, kadar davčni zavezanci ne vodijo obveznega knjigovodstva in tako ne morejo oziroma nočejo predložiti dokumentacije, ki bi omogočala ugotovitev višine davčne obveznosti ali pa vse, kar so predložili, ne ustreza dejansko opravljeni gospodarski dejavnosti. Ocena davčne osnove je $v$ davčnih inšpekcijskih postopkih relativno pogosta, vendar bi morala biti izjemen ukrep davčnih organov, saj je problematična predvsem zato, ker se razteza od gotovosti do verjetnosti. Temeljni cilj vsakega postopka cenitve je ugotoviti davčno osnovo, ki je najbližja resničnosti. Gre za to, da

28 Drugi odstavek 138. člena ZDavP-2.

29 Jerovšek, 2004, str. 4. 
Polona Kovač, Tina Konečnik

\section{Novosti davčnega inšpekcijskega nadzora po ZDAVP-2}

želimo s pomočjo cenitve doseči približen rezultat, za katerega domnevamo, da je najverjetneje pravilen ${ }^{\mathbf{3 0}}$. Pri tem je treba poudariti, da mora biti domnevni razlog cenitve pravilen in upravičen, postopek cenitve pa mora biti izveden brezhibno $^{\mathbf{3 1}}$. Naslednji dve odločitvi Upravnega sodišča potrjujeta upravičenost ugotavljanja višine davčne obveznosti z oceno:

- Sodba Upravnega sodišča št. U 2264/2004-12, z dne 13. 12. 2005: "Ker davčni organ s tožnikovo davčno napovedjo ni razpolagal, prav tako tožnik ni predložil poslovnih knjig, je po presoji sodišča pravilen tudi postopek izvedbe ocene davčne osnove, saj je prvostopni organ izhajal iz podatkov zbranih $v$ ugotovitvenem postopku in uradnih podatkov. Tožnik pa zgolj ob pavšalnih navedbah...ni z ničimer dokazal, da je davčna osnova nižja."

- Sodba Upravnega sodišča št. U 686/2001, z dne 10. 1. 2005: "Davčni organ ugotovi davčno osnovo z oceno, če ugotovi, da temelji davčna napoved oz. davčni obračun na neresničnih, nepravilnih podatkih oz. če davčni zavezanec ne predloži poslovnih knjig in evidenc ali pa so le-te vsebinsko napačne, ali če kažejo bistvene formalne pomanjkljivosti, ki opravičujejo sum glede njihove vsebinske pravilnosti. Tožena stranka sicer lahko pri cenitvi uporabi različne metode, vendar jih mora obrazložiti tako, da ni nobenega dvoma v pravilnost izračuna."

Po opravljenem davčnem inšpekcijskem nadzoru in pred sestavo zapisnika, mora davčni inšpektor z zavezancem opraviti sklepni pogovor. Zavezanec za davek mora biti na sklepni pogovor povabljen z dopisom. Namen sklepnega pogovora je predvsem zavezanca seznaniti z ugotovitvami davčne inšpekcije, ga opozoriti na sporna dejstva ter na pravne učinke teh ugotovitev ${ }^{\mathbf{3 2}}$. Sklepni pogovor ima posvetovalen in preventiven značaj. $V$ njem se namreč zavezancu prikaže: (1) katera sporna dejstva, ki vplivajo na obdavčenje, je davčni organ ugotovil, (2) kakšne bodo pravne posledice ugotovitev nadzora (npr. ugotavljanje prekrškovne oz. kazenske odgovornosti) in (3) kakšni bodo davčni učinki ugotovitev (kako in koliko bodo ugotovitve vplivale na višino davčne obveznosti). Namen sklepnega pogovora je dvojen - (1) uresničevanje načela materialne resnice in načela zaslišanja stranke ter (2) priprava zavezanca na obrambo zoper odločbo oz. njeno realizacijo. Sklepni pogovor je zakonsko obvezen. ZDavP-2 v 139. členu določa, da sklepnega pogovora ni treba opraviti, v kolikor

30 Domnevna verjetnost, ki meji na visoko gotovost, je že sama po sebi zadostna (Wakounig, 1998, str. 23).

31 Po Wakounig, 1998, str. 18-21.

32 Mužina, 2004, str. 344. 
se mu davčni zavezanec izogiba ali pa rezultat davčnega inšpiciranja ne vpliva na obdavčenje. $V$ kolikor se med inšpekcijskim pregledom ne ugotovi dejstev, ki bi imela vpliv na višino davčne obveznosti, je treba sklepni pogovor izvesti le $\checkmark$ primeru izrecne želje zavezanca ${ }^{\mathbf{3 3}}$.

Po opravljenem sklepnem pogovoru oz. po končanem ugotovitvenem postopku, davčni organ sestavi t. i. sumarni zapisnik. "Zapisnik o inšpekcijskem pregledu je listina, $v$ kateri so šele $v$ celoti zbrana in na ustrezen način protokolirana vsa relevantna dejstva, zbrana pri konkretnem inšpekcijskem pregledu" (Sodba Upravnega sodišča. št. U 1774/2004-6, z dne 19.12.2005). Zapisnik o davčnem inšpekcijskem nadzoru ureja ZDavP-2 v 140. členu, kjer je določeno, da se zapisnik vroči davčnemu zavezancu najkasneje $v 10$ dneh po končanem pregledu. Zakon dopušča pripombe na zapisnik, in sicer $v 20$ dneh po vročitvi, ta rok pa se lahko podaljša za največ $10 \mathrm{dni}^{\mathbf{3 4}}$. $\vee$ davčnem inšpekcijskem postopku ločujemo med "glavnim" in "dodatnim" zapisnikom. Dodatni zapisnik je zapisnik, ki ga je davčni organ dolžan sestaviti $\vee 30$ dneh od prejema pripomb ( $v$ katerih zavezanec navaja nova dejstva in dokaze) na glavni zapisnik. $V$ odločbi davčni organ navede: "Na ugotovitve $\vee$ zapisniku $O$ davčnem inšpekcijskem nadzoru je zavezanec dne ... podal pripombe, ki se ( $v$ celoti ali delno ali ne) upoštevajo, ker ... V zvezi s pripombami je davčni organ sestavil dodatni zapisnik številka ... z dne ..., na katerega zavezanec ni dal pripomb". Če so pripombe podane, se je treba o njih izreči v odločbi. Zapisnik ureja tudi ZUP, ki ga opredeljuje kot javno listino, ki ima močno dokazno funkcijo (74-82. člen). Pri sestavi zapisnika o davčnem inšpekcijskem nadzoru je treba upoštevati določbe ZDavP-2, ki je $\vee$ razmerju do ZUP specialen predpis. Navedeno potrjuje sodba Upravnega sodišča RS, U 2005/2002-8, z dne 21. 2. 2005: "Glede ugovora tožnika o pisanju zapisnika o davčnem postopku po določbah 74. in 78. člena ZUP sodišče ocenjuje, da je stališče tožene stranke, da mora davčni organ $\vee$ davčnih stvareh primarno uporabljati ZDavP kot specialen predpis glede na ZUP, pravilno. Tudi 15.a člen ZDavP je potrebno razumeti kot specialnega glede na splošnega in je $v$ njem izrecno zapisano, da se zapisnik o davčnem postopku inšpekcijskega nadzora sestavi in vroči davčnemu zavezancu najpozneje $v$ 15-ih dneh po končanem pregledu..." Med samim inšpekcijskim nadzorom se lahko ugotovijo posamezna dejstva in dokazi, ki vplivajo na obdavčenje drugih oseb ali istega zavezanca $\vee$ drugi zadevi. Taka dejstva in dokaze je treba poslati pristojnemu davčnemu organu, ki uvede obnovo postopka (89. člen ZDavP-2).

33 Razen kadar bi bilo takšno postopanje $v$ nasprotju z načelom ekonomičnosti postopka. 34 Rok za pripombe na zapisnik se lahko podaljša zgolj na podlagi utemeljene pisne zahteve zavezanca, ki jo mora predložiti pred iztekom roka. O podaljšanju roka davčni organ izda sklep (1. odstavek 140. člena ZDavP-2). 


\section{Novosti davčnega inšpekcijskega nadzora po ZDAVP-2}

\subsection{Izdaja odločbe}

Davčni organ ukrepa zoper zavezance, če se ti na kakršenkoli način izogibajo davčnim obveznostim.

Davčni inšpekcijski postopek se lahko zaključi na več načinov, tj. najpogosteje z izdajo (1) odmerne odločbe o spremenjeni davčni obveznosti zavezanca, (2) ureditvene odločbe po pravilih ZIN, če so ugotovljene nepravilnosti, ki pa ne vplivajo na višino davčne obveznosti, ali (3) sklepa o ustavitvi postopka po ZIN, če pomanjkljivosti $v$ nadzoru ni bilo ugotovljenih (28. člen ZIN). Kadar se $v$ inšpekcijskem postopku ugotovi, da je davčna obveznost manjša, kot jo je npr. zavezanec predvidel v predloženem obračunu, mora inšpektor $v$ skladu z načeli zakonitosti (vsak plača toliko davka, kot to določa zakon, ne več in ne manj), materialne resnice (obveznost temelji na resničnih dejstvih) in varstva pravic strank (dejstva se ugotavlja tako $v$ breme kot $v$ korist strank) izdati (4) odločbo o vračilu davka. Kadar bi inšpektor po navedenih načelih ugotovil, da je zavezanec plačal previsok davek npr. na podlagi obračuna zaradi očitne napake, izda (5) odločbo na podlagi 90. člena tega zakona (posebni primeri razveljavitve, spremembe oz. odprave), saj je treba vzpostaviti pravno podlago za vračilo preplačila zaradi previsoko odmerjenega davka. Če je ugotovljena davčna obveznost nižja od 10 evrov, se pa (6) ne odmeri, razen če gre $v$ korist lokalne skupnosti: postopek se zaključi po 50. členu ZDavP-2 le z uradnim zaznamkom. $\checkmark$ takem primeru bi namreč stroški vodenja postopka (in izterjave) prekomerno presegli vrednost dolga. Kadar se izda ureditvena odločba po ZIN, tj. odločba o odpravi pomanjkljivosti oz. nepravilnosti, ki ne vplivajo na višino davčne obveznosti, ta $v$ izreku nima sestavnih delov po 80. členu tega zakona, temveč po ZIN in ZUP odločitev o zadevi (odredba o odpravi nepravilnosti), rok za izvedbo ukrepa, odločitev o stroških in klavzulo o nesuspenzivnosti pritožbe. Rok mora biti po načelu sorazmernosti (7. člen ZIN) določen ne le glede na težo kršitve, ampak tudi izvedljiv za konkretnega zavezanca, da naloženo opravi oz. napako odpravi.

Odločba je akt, s katero organ odloči o pravici, obveznosti ali pravni koristi stranke $\vee$ postopku. Je strogo formalen upravni akt, ker je zanjo predpisana stroga obličnost. ZDavP-2 določa najdaljše roke za izdajo odločbe $v$ davčnem inšpekcijskem postopku. Kot splošno pravilo je določen šestmesečni rok, $v$ izjemnih primerih pa lahko inšpekcijski postopki trajajo tudi do devet mesecev. Ti primeri so po 141. členu ZDavP-2:

- kadar gre za inšpiciranje povezanih oseb,

- $\quad$ kadar se inšpicira zavezance za davek, ki so zavezani k reviziji letnih poročil, 


\section{Novosti davčnega inšpekcijskega nadzora po ZDAVP-2}

- kadar davčni organ ceni davčno osnovo,

- ko zavezanec za davek ne predloži dokumentacije in ne da pojasnil v zvezi s predmetom davčnega inšpekcijskega nadzora ali ovira davčni inšpekcijski nadzor ter

- $\quad$ ko gre za sočasni davčni nadzor, ki hkrati poteka v več državah članicah $\mathrm{EU}^{35}$.

Z vidika preizkusa zakonitosti odločbe sta pomembna predvsem vsebina in določnost izreka ter sama obrazložitev ${ }^{\mathbf{3 6}}$. Bistvene kršitve pravil postopka so namreč pogoste predvsem zaradi nemožnosti preizkusa odločbe, predvsem v primeru pomanjkljive obrazložitve ${ }^{\mathbf{3 7}}$, kot primer sodba Upravnega sodišča RS, U 1900/2002-7, z dne 4. 4. 2005: "Niti obrazložitev prvo niti drugostopenjske odločbe nima vsebine, da bi stranki omogočala, da razloge odločitve izpodbija, prav tako pa tudi sodišče $v$ danem primeru pravilnosti in zakonitosti izpodbijane odločbe ne more preizkusiti v smislu 1. člena ZUS. Da bi bila možna naknadna sodna presoja pravne pravilnosti odločbe upravnega organa mora biti upravna odločba ustrezno obrazložena." Sestavine odločbe so urejene v ZUP-u, vendar lahko področni zakon posamezne dele izrecno izvzame ali uredi drugače. Tako se glede davčne odločbe drugačna ureditev $\vee$ ZDavP-2 $\vee$ razmerju do ZUP nanaša predvsem na izrek odmerne odločbe ${ }^{\mathbf{3 8}}$, ki je tudi najpomembnejši del upravne odločbe. Nadalje ZDavP-2 določa, da se izda odmerno odločbo na podlagi zapisnika v roku 30 dni od dneva prejema pripomb na zapisnik ${ }^{\mathbf{3 9}}$. Gre za rok, ki je za davčni organ zgolj instrukcijski; kot primer sodba Upravnega sodišča št. U 1793/2004-13, z dne 19. 12. 2005: "Kot pravilno poudarja že tožena stranka, je rok za izdajo odločbe instrukcijski in ne prekluziven, kar pomeni, da je mogoče izdati odločbo tudi po poteku predpisanega roka, ne da bi to vplivalo na njeno zakonitost. To pa pomeni tudi, da takšna izdana odločba ni nedovoljeno dejanje in da je zato ni mogoče izpodbijati iz razloga ničnosti po 5. točki 1. odstavka 279. člena ZUP. " Enako poudarja tudi sodba Upravnega sodišča, št. U 137/2004, z dne 20.1.2006: "...rok za izdajo glavne odločbe je instrukcijski in njegova prekoračitev ni sankcionirana in ima $v$ tem primeru tožeča stranka možnost vložitve tožbe zaradi molka organa, drugih posledic pa zakon ne določa." Pomembnejša sestavina odločbe je tudi pouk o pravnem sredstvu,

$35 \mathrm{~V}$ primeru četrte in pete točke omejitve o izdaji odločbe $v$ šestih ali $v$ devetih mesecih ne veljajo (četrti odstavek 141. člena ZDavP-2).

36 Načelo obrazložitve odločitve upravnih oblasti, je prav tako močno poudarjeno $v$ okviru načel upravnega postopka v evropskem upravnem pravu. Gre za "Principle of care» in v okviru tega "Duty to give reasons" (po Nehl, 1999, str. 119).

37 Kovač, 2006a, str. 290, po Pirnat, 2004

38 80. člen ZDavP-2

39 1. odstavek 84. člena ZDavP-2 
Polona Kovač, Tina Konečnik

Novosti davčnega inšpekcijskega nadzora po ZDAVP-2

s katerim se stranko pouči, da lahko zoper odločbo v določenem roku vloži pritožbo. Pri tem je treba omeniti, da pritožba zoper davčno odločbo ne zadrži njene izvršitve gre za klavzulo o nesuspenzivnem učinku vložene pritožbe, kot obvezni sestavini izreka davčne odločbe.

\subsection{Pravna sredstva zoper davčno odločbo}

Glede varstva pravic Ustava Republike Slovenije v Republiki Sloveniji zagotavlja, in sicer $\vee 22$. členu, enako varstvo pravic $\vee$ postopku pred sodišči in pred drugimi državnimi organi, organi samoupravnih lokalnih skupnosti in nosilci javnih pooblastil, ki odločajo o njegovih pravicah, dolžnostih ali pravnih interesih. Pravico do pritožbe pa ustava podrobneje določi v 25. členu. Pravno sredstvo zoper odločitve oblastnih upravnih organov mora biti zagotovljeno; v nekaterih primerih lahko zakon izključi pravico do pritožbe, vendar se mora $v$ takšnem primeru zagotoviti drugo pravno sredstvo. Zoper davčno odločbo je mogoča pritožba na drugostopenjsko Ministrstvo za finance ${ }^{\mathbf{4 0}}$, in sicer po novem ZDavP-2, v roku 30-ih dneh od dneva vročitve odločbe. $V$ davčnih zadevah pritožba ne zadrži izvršitve ${ }^{41}$. Pritožba se lahko vloži po 237. členu ZUP zaradi zmotno ali nepopolno ugotovljenega dejanskega stanja, kršitev pravil postopka ter kršitve ali napačne uporabe materialnega prava. $V$ upravnem postopku pritožba ni mogoča na tretjo stopnjo - odločba druge stopnje je dokončna in se lahko izpodbija samo še z izrednimi pravnimi sredstvi in s tožbo na upravno sodišče.

Z izrednimi pravnimi sredstvi, je mogoče po dokončnosti ali pravnomočnosti odločbe, izjemoma pa pred tem, izpodbijati odločbo zaradi hujših napak, ki so kot razlog navedene $v$ posameznem izrednem pravnem sredstvu. $V$ davčnem inšpekcijskem postopku je mogoče uporabiti šest izrednih pravnih sredstev in sicer:

- odprava in razveljavitev oziroma sprememba odločbe po nadzorstveni pravici,

- obnova davčnega postopka,

40 Kot primer lahko navedemo, da je pritožbeni postopek v avstrijskem davčnem pravu podoben našemu. Pritožbeni rok traja en mesec od vročitve odločbe, pritožba se prav tako vloži na drugi stopnji. Pritožba prav tako ne zadrži izvršitve, lahko pa se zaprosi za zadržanje pobiranja in izterjave dajatve, kadar davčni zavezanec lahko dokaže, da bo pritožba uspešna. Proti odločbam drugostopenjskih organov v Avstriji redna pravna sredstva niso več dopustna, davčni zavezanec pa ima pravico, da se $v$ šestih tednih (od vročitve drugostopenjske odločbe) pritoži na upravno oziroma ustavno sodišče (po Wakounig, 1999, str. 1479 - 1484).

$41 \mathrm{~V}$ kolikor davčni organ oceni, da bi bilo pritožbi zoper odločbo mogoče ugoditi, lahko po uradni dolžnosti odloži davčno izvršbo do odločitve o pritožbi. 
- posebni primeri odprave, razveljavitve in spremembe odločbe,

- sprememba ali odprava odločbe v zvezi z upravnim sporom,

- izredna razveljavitev,

- ničnost odločbe.

ZDavP-2 posebej določa odpravo in razveljavitev odločbe po nadzorstveni pravici, obnovo postopka ter posebne primere razveljavitve ali spremembe odločbe ${ }^{\mathbf{4 2}}$. Glede vseh preostalih izrednih pravnih sredstev pa je treba subsidiarno upoštevati določbe ZUP.

Če se davčna odločba odpravi, se odpravijo tudi vse pravne posledice, ki so z odločbo nastale. Odprava torej učinkuje retroaktivno oz. za nazaj (ex tunc, pro praeterito). Z odpravo odločbe se vzpostavi pravno stanje, ki je obstajalo pred izdajo davčne odločbe (status quo ante). $\vee$ kolikor gre za razveljavitev odločbe, se pravne posledice, ki so z odločbo nastale, sicer ne odpravijo, ne morejo pa iz razveljavljene odločbe nastati druge pravne posledice ${ }^{\mathbf{4 3}}$. Razveljavitev učinkuje torej za naprej (ex nunc, pro futuro). Če sprememba davčne obveznosti vpliva na davčno obveznost $v$ obdobjih, ki sledijo davčnemu obdobju, na katero so sprememba, odprava ali razveljavitev nanaša, davčni organ odloči tudi o davčni obveznosti $v$ teh obdobjih.

\section{Zaključek}

Pisanje prispevka o davčnem inšpekcijskem postopku sovpada s sprejemom novega zakona ZDavP-2, ki je pričel veljati 17. 11. 2006, uporablja pa se od 1.1.2007, razen za primere, ki so izjemoma urejeni $\vee$ prehodnih določbah. Zaradi navedenega so $v$ prispevku predstavljene nekatere pomembnejše spremembe, ki jih z vidika davčnega inšpiciranja prinaša omenjeni zakon. Med njimi je treba izpostaviti predvsem ureditev načel davčnega postopka, preureditev samoprijave, odpravo obvestila o začetku nadzora s strani davčnega organa, podaljšanje roka za pritožbo zoper odločbo izdano $\vee$ davčnem inšpekcijskem postopku, omejitev časa trajanja davčnega nadzora itd. Novi zakon naj bi odpravil dvoumnost, ki je bila davčni zakonodaji mnogokrat očitana, prav tako naj bi odpravil nepotrebno administriranje ter poenostavil davčni postopek.

Temeljni cilj davčnega inšpekcijskega nadzora je davčnim zavezancem onemogočiti nezakonito izogibanje plačevanja davkov. Pri tem je treba poudariti,

42 88., 89., 90. člen ZDavP-2

43 po Postogna, 2004, str. 29 


\section{Polona Kovač, Tina Konečnik \\ Novosti davčnega inšpekcijskega nadzora po ZDAVP-2}

da pri morebitni skušnjavi davčnega zavezanca, da bi ravnal nezakonito in utajil davke, pomembno vlogo odigra sicer tudi sama morala davčnega zavezanca, predvsem pa (ne)učinkovitost davčnega nadzora. Cilj vsake davčne uprave je spodbujati prostovoljno obdavčenje, pri čemer je nepogrešljivo orodje predvsem učinkovit sistem sankcij oziroma glob.

Davčni inšpekcijski postopek je poseben upravni postopek, kjer je močno poudarjen konflikt med javno in zasebno koristjo. Treba pa je upoštevati, da je delovanje inšpekcij izrazito usmerjeno v varovanje javnega interesa. Kljub temu pa davčni inšpektorji ne bi smeli delovati zgolj represivno, temveč bi morali zavezancem pomagati pri izpolnjevanju njihovih davčnih obveznosti ter jim omogočiti zavarovanje pravic v postopku davčnega inšpekcijskega nadzora.

Dr. Polona Kovač je višja predavateljica na Fakulteti za upravo Univerze v Ljubljani. Doktorirala je I. 2005 na Pravni fakulteti v Ljubljani. Prednostno se ukvarja z upravnimi postopki (splošni upravni postopek, davčni postopek, uveljavljanje pravic iz socialnih zavarovanj, inšpekcijski nadzor idr.) in nasploh s pravno ureditvijo javne uprave. Poleg tega je dejavna na področju kakovosti, zlasti rabe modelov odličnosti v javnem sektorju. S slednjim se ukvarja od I. 2001, od tega do I. 2004 kot nacionalna koordinatorica za uvajanje modela CAF v slovensko upravo, od I. 2005 dalje pa kot razsodnica v postopku Priznanja RS za poslovno odličnost. Redno objavlja $v$ strokovni literaturi in sodeluje na domačih in tujih konferencah. Je izvajalka vrste seminarjev in delavnic na področju kakovosti in pravne ureditve javne uprave, od I. 2005 je tudi predstojnica za izobraževanje javnih uslužbencev na Fakulteti za upravo.

Tina Konečnik je podiplomska študentka 2-stopenjskega magistrskega študija Uprava na Fakulteti za upravo. Dodiplomski šudij je prav tako zaključila na Fakulteti za upravo, kjer je bila zaradi izkazanih nadpovprečnih študijskih dosežkov izbrana v študijskem letu 2004/2005 za najuspešnejšo študentko letnika, študijskem letu 2005/2006 pa je prejela fakultetno priznanje za najuspešnejšo diplomantko. 


\section{Literatura in viri}

- Administration and you (1996): Principles of administrative law concerning the relations between administrative authorities and private persons, Council of Europe, Strasbourg.

- Grivec J. (2005): Prispevek davčne inšpekcije k javnofinančnim prihodkom proračuna, Specialistično delo, Univerza v Ljubljani, Fakulteta za upravo.

- Jerovšek, T. (2005): Nekatere sugestije na drugačno ureditev davčnega postopka, Javna uprava št. 2/3, str. 286-299.

- Jerovšek, T. (2004): Novi davčni postopek, CD zbornik posvetovanj Dnevi slovenske uprave, Fakulteta za upravo.

- Konečnik, T. (2006): Davčni inšpekcijski nadzor, Diplomsko delo, Univerza v Ljubljani, Fakulteta za upravo.

- Kovač, P. (2006 b): Načela davčnega postopka, Pravna praksa št. 29-30, str. 8-10.

- Kovač, P. (2006 a): Postopkovna vprašanja davčnega inšpekcijskega nadzora med učinkovitostjo in varstvom pravic zavezancev, Javna uprava št. 2/3, str. 273-298.

- Kruhar Puc, R. (2004): Ko nas obišče davčni inšpektor, Založniška hiša Primath d.o.o. Ljubljana, elektronski vir.

- $\quad$ Kruhar Puc R., Galič J. (2006): Najpogostejše ugotovitve davčnih inšpektorjev na terenu (s primeri iz prakse z upoštevanjem stare in nove zakonodaje), Založniška hiša Primath, Ljubljana.

- Mužina, A. (2004): Davčni inšpekcijski postopek v zakonodaji in sodni praksi, Javna uprava št. 2, str. 336-356.

- Nagode J. (2005): Koga inšpicirati : Kdo odloča o tem?, Dacar, glasilo Davčne uprave Republike Slovenije, letnik 7, št. 2-3, str.12-14.

- Nehl H. P. (1999): Principles of Administrative Procedure in EC Law, Oxford.

- Silvani C., Baer C. (1997): Designing a Taw Administration Reform Strategy, Wxperiences and Guidelines, IMF Working Paper, WP/97/30, Washington.

- Šinkovec, J., Tratar, B. (2002): Zakon o davčnem postopku s komentarjem, Oziris, Ljubljana.

- Tratar, B., Kruhar Puc, R.: Novi davčni postopek, Zakon o davčnem postopku (ZDavP-1) s pojasnili in primeri iz prakse, Legat, Lesce, 2005.

- Veršnik N. (2004): Vplivni dejavniki davčnih utaj, Davčno finančna praksa, Davčni inštitut, letnik $V$, številka 6, str. 14-16. 
Polona Kovač, Tina Konečnik

Novosti davčnega inšpekcijskega nadzora po ZDAVP-2

- Postogna J. (2004): Davčno finančna praksa, Davčni inštitut, letnik V, številka 12, str. 29.

- Wakounig, M. (1998): Davčno inšpiciranje in cenitev davčne osnove, MFB Consulting, Ljubljana.

- Wakounig M, (1999): Pritožbeni postopek v Avstrijskem davčnem pravu, Podjetje in delo 6-7/1999/XXV, revija za gospodarsko, delovno in socialno pravo, Dnevi slovenskih pravnikov od 14. do 16. oktobra, Portorož, str. 1479-1484. 


\section{SUMMARY}

\section{NOVELTY OF THE TAX PROCEDURE ACT (official Slovenian abbreviation: ZDavP-2)}

The tax procedure is the entire procedure regulated by the Tax Procedure Act (official Slovenian abbreviation: ZDavP-2), which all tax offices in the Republic of Slovenia must comply with when deciding on tax matters, as must the Ministry of Finance as the second-instance body, and other bodies in tax matters. Tax inspection is inspection of compliance with regulations in the field of taxation and with the ZDavP-2, and includes controlling tax returns by tax bodies, supervision and control in accordance with the law regulating customs, tax inspection and tax investigation. The objective of tax inspection, as a form of external inspection, is to verify the operations of taxable persons, prevent unlawful avoidance of paying taxes, and to detect tax evasion. The provisions of the Administrative Procedure Act (ZUP) and the Inspection Act (ZIN) apply on a subordinate basis to tax inspection procedures, as specific administrative procedures, as do the supranational regulations of the European Union and the individual taxation act. Tax inspection is implemented under the auspices of the Tax Administration of the Republic of Slovenia, which is an agency of the Ministry of Finance. The organisation of the Tax Administration is regulated by the Tax Administration Act (ZDS-1). Tax inspection is implemented by tax inspectors, who require special authorisations to perform their work. An inspector has the right and duty on detecting a violation to issue an appropriate measure, where the principle of subsidiarity must be taken into account. This means that measures defined by an individual taxation act must first be taken into account, followed by the Tax Procedure Act (ZDavP-2) and then by the Inspection Act (ZIN). In 2005 the Tax Administration also assumed the tasks of an administrative offence authority, which were previously executed by courts. Since 2005, tax inspectors have been authorised to conduct fast-track misdemeanours procedures, in addition to administrative procedures.

The writing of this paper on the tax inspection procedure has coincided with the adoption of the new Tax Procedure Act (the ZDavP-2), the provisions of which will apply from 1 January 2007. The new act (ZDavP-2) introduced some significant amendments to the tax inspection procedure to the previous act (ZDavP-1). Those that are worthy of 
Polona Kovač, Tina Konečnik

Novosti davčnega inšpekcijskega nadzora po ZDAVP-2

note in terms of tax inspection are the reorganisation of self-declaration, the abolition of the notification on start of inspection, arrangements for the principles of the tax procedure, restrictions on the duration of inspection to six months, or a maximum of nine months, and the extension of the time limit for an appeal against a decision issued tax inspection to 30 days.

The new act abolishes the obligation on tax bodies to send a notification on start of inspection to taxable persons. Tax inspection procedures start with the issue of a written resolution on the start of inspection, which must be submitted to the taxable persons eight days in advance. The taxable person has the right to make a self-declaration until the start of inspection. The essence of self-declaration is to promote voluntary taxation, and taxable persons are not punished for a misdemeanour if they self-declare, even if they failed to act in accordance with tax legislation. However, this only applies if the correct data is submitted to the tax authority before the tax inspection starts. The books of account and documentation must be submitted to the tax authority for the purposes of inspection, which must be kept correctly, as the tax base is defined on the basis of the data they contain. Accounting documents must be authentic, and must make the nature and volume of the business event clear and unequivocal. Taxable persons are also obliged to submit the data by the duty to provide data defined within the new Tax Procedure Act (ZDavP-2).

Tax inspection procedures are generally lengthy declarative procedures. The major contribution to this is the potential appraisal of the tax base, which the tax authority assesses if the tax liability cannot be defined on the basis of the books of account and documentation submitted. In that case, the tax authority must prove the facts on which basis it issues its decision. However, the act charges the taxable person with a "reversed burden of proof" whereby in such cases the taxable person must prove any facts on which basis the tax base should be reduced. On completion of the declaratory procedure and taking of evidence, the tax authority holds a concluding discussion with the taxable person, which is required in order to protect the principle of parties to a procedure being given a hearing. The next stage is the production of a tax inspection record, which is a public document and a significant item of evidence. It collects and officially sets out all the relevant facts gathered in a specific inspection. The new act (ZDavP-2) states in terms of the duration of a tax inspection 
procedure that procedures (in exhaustively listed cases) can last up to nine months or longer, but as a general rule provides for a six month time limit.

Tax procedures can be terminated in three different ways: by a decision terminating a procedure, with a declarative decision, while the most frequent conclusion of a first-instance tax inspection is the issuing of a tax assessment decision ordering the taxable person to settle a tax liability. The components of a decision are regulated by the Administrative Procedure Act (ZUP), however, the sectoral act can provide for exemptions or set out different arrangements. Alternative arrangements to those defined in the Administrative Procedure Act (ZUP) that are set out in the new act (ZDavP-2) in relation to tax decisions refer primarily to the operative part of a tax administration decision. Taxable persons have the right to appeal against a tax decision. An appeal is the only regular legal remedy on which the Ministry of Finance decides at the second instance. The new act (ZDavP-2) extends the time limit for an appeal against a tax inspection decision to 30 days following the serving of a first-instance decision. Extraordinary legal remedies may also be applied within a tax inspection procedure, where the provisions of the Administrative Procedure Act (ZUP) must be taken into account, subordinately.

Further innovations of the new act (ZDavP-2) included arrangements relating to tax procedure principles. The principles may be divided into those primarily binding on the tax authority, and those binding on taxable persons. The more significant principles binding on the tax authority include the principle of legality, the principle of substantive truth, the principle of proportionality, and the protection of tax secrecy. In addition to the principles defined in the new act (ZDavP-2), during an inspection procedure a tax authority must also take into account the principles established by the case of the European courts and the principles set out in the Inspection Act (ZIN) and the Administrative Procedure Act (ZUP). The Inspection Act (ZIN) lays down the principles of independence and proportionality, the principle of the protection of public and private interests and the public trial principle, while the major principles of the Administrative Procedure Act (ZUP) relating to tax inspection are the principles of the right of parties to a hearing, which is heavily emphasised in European administrative law, and the principle of the free assessment of evidence.

As has been emphasised on many occasions, the tax inspection procedure is a special administrative procedure, where the conflict between 
Polona Kovač, Tina Konečnik

Novosti davčnega inšpekcijskega nadzora po ZDAVP-2

the public and private interest is strongly emphasised, and inspectors are required to protect the public interest. Despite this, inspectors should not only act repressively, but should also help taxable persons to settle their tax liabilities, and provide them with effective protection of their rights within tax inspection procedures. 